\title{
Efektivitas Baby Massage Dan Baby Gym Terhadap Kualitas Tidur Bayi Usia 3-6 Bulan
}

\author{
Rose Nurhudhariani, Yeni Dwi Ratnasari, Sonhaji, Siti Nur Umariyah Febriyanti \\ Sekolah Tinggi Ilmu Kesehatan Karya Husada Semarang,JL. Kompol R. Soekanto No. 46, Sambiroto, Kec. Tembalang, \\ Kota Semarang, Jawa Tengah, Telp. (024) 6724581 \\ rose.djogja@gmail.com
}

\begin{abstract}
ABSTRAK
Baby massage dan baby gym adalah upaya untuk meningkatkan kualitas tidur pada bayi. Masalah tidur pada bayi di Indonesia cukup banyak, yaitu sekitar $44,2 \%$ bayi mengalami gangguan tidur seperti sering terbangun di malam hari. Namun lebih dari $72 \%$ orang tua menganggap gangguan tidur bukan suatu masalah atau hanya masalah kecil, hal tersebut diungkapkan oleh sebuah penelitian pada tahun 2014-2015 yang dilaksanakan di lima kota besar di Indonesia Berdasarkan data awal terdapat 20 bayi yang datang ke posyandu dan ditemukan 17 bayi yang mengalami gangguan tidur. Tujuan penelitian untuk mengetahui efektivitas baby massage dan baby gym terhadap kualitas tidur bayi usia 3-6 bulan di Desa Talang Tegal. Jenis penelitian adalah kuantitatif dengan two group pre and post test design. Sampel sebanyak 34 bayi yang diberikan perlakuan baby massage dan baby gym dilakukan selama 2 minggu 3x seminggu, untuk baby massage 15 menit sedangkan untuk baby gym 5 menit. Terdapat pengaruh baby massage terhadap kualitas tidur bayi usia 3-6 bulan dengan $p$ value 0.000 . Terdapat pengaruh baby gym terhadap kualitas tidur bayi usia 3-6 bulan dengan $p$ value 0,001 . Tidak terdapat perbedaan efektivitas baby massage dan baby gym terhadap kualitas tidur bayi usia 3 - 6 bulan.
\end{abstract}

Kata kunci : baby gym; baby massage; kualitas tidur bayi

\section{The Effectiveness of Baby Massage And Baby Gym on Sleep Quality of 3-6 Months Baby}

\begin{abstract}
Baby massage and baby gym are efforts to improve the quality of sleep in babies. There are quite a number of sleep problems in infants in Indonesia, which is around $44.2 \%$ of infants experiencing sleep disorders such as frequent awakenings at night. However, more than $72 \%$ of parents consider sleep disturbances not a problem or just a minor problem, this was revealed by a 2014-2015 study conducted in five major cities in Indonesia. Based on initial data there were 20 babies who came to the Integrated Healthcare Centre and found 17 babies with sleep disorders. The purpose of the study was to determine the effectiveness of baby massage and baby gym on the sleep quality of baby aged 3-6 months in Talang Tegal Village. This type of research was quantitative with two groups pre-post test design. A sample of 34 babies who were given baby massage and baby gym treatment was carried out for 2 weeks 3 time each week, for baby massage 15 minutes while for baby gym 5 minutes. There is an effect of baby massage on the sleep quality of babies aged 3-6 months with a $p$ value of 0.000 . There is an effect of baby gym on the sleep quality of babies aged 3-6 months with a $p$ value of 0.001 . There is no difference in the effectiveness of baby massage and baby gym on the sleep quality of babies aged 3-6 months.
\end{abstract}

Keywords: baby gym; baby massages; sleep quality of baby 


\section{LATAR BELAKANG}

Masa bayi merupakan masa emas dalam pencapaian pertumbuhan dan perkembangan anak yang tentunya memerlukan perhatian khusus. Salah satu faktor yang mempengaruhi tumbuh kembang bayi adalah tidur dan istirahat. Tidur nyenyak sangat penting bagi pertumbuhan bayi, karena saat tidur pertumbuhan otak bayi mencapai puncaknya. Selain itu pada saat tidur tubuh bayi memproduksi hormon pertumbuhan tiga kali lebih banyak pada saat bayi tidur dibandingkan ketika bayi terbangun (Griya Sehat Indonesia, 2015).

Bayi yang mengalami gangguan tidur akan mengalami gangguan yang sama di masa-masa selanjutnya terutama pada masa pertumbuhan.Gangguan tidur pada bayi usia 36 bulan yang tidak teratasi maka akan terjadi gangguan tidur pada bayi sampai usia 12 bulan (Satte, 2017).

Masalah tidur pada bayi di Indonesia cukup banyak, yaitu sekitar $44,2 \%$ bayi mengalami gangguan tidur seperti sering terbangun di malam hari. Namun lebih dari $72 \%$ orang tua menganggap gangguan tidur bukan suatu masalah atau hanya masalah kecil, hal tersebut diungkapkan oleh sebuah penelitian pada tahun 2014-2015 yang dilaksanakan di lima kota besar di Indonesia (Jakarta, Bandung, Medan, Palembang dan Batam) (Simanungkalit, 2019).

Hal yang bisa dilakukan untuk menurunkan gangguan tidur pada bayi diantaranya adalah melalui konsultasi dengan dokter, penyuluhan tentang cara mengatasi gangguan tidur, serta melakukan pemijatan pada bayi oleh orang tua. Pijat bayi bermanfaat merangsang syaraf motorik, memperbaiki pola tidur, membantu pencernaan dan meningkatkan ketenangan emosional anak, selain menyehatkan tubuh dan otot-otot. Bayi yang dipijat dengan baik dan teratur dapat tumbuh lebih sehat dan berkembang lebih baik (Tiffany, 2015).

Berdasarkan survey pendahuluan di Desa Talang Kecamatan Talang Kabupaten Tegal terdapat 20 bayi yang datang ke posyandu dan menemukan 17 bayi yang mengalami gangguan tidur. Dari hasil wawancara dengan 17 ibu yang bayinya mengalami gangguan tidur tadi menganggap bahwa masalah gangguan tidur pada bayinya adalah hal yang biasa, mereka tidak mengetahui kalau gangguan tersebut akan berdampak pada pola tidur dan mengganggu pertumbuhan dan perkembangan bayi, ada 10 ibu diantaranya dari bayi berusia 3-6 bulan mengatakan bahwa agar bayinya tidak rewel dan bisa tidur nyenyak mereka memberikan makan pada bayinya sehingga mempengaruhi cakupan ASI eksklusif di Desa Talang masih rendah yaitu $40 \%$.

Pijat bayi akan membuat bayi tidur lebih leleap dan meningkatkan kesiagaan (alertness) atau konsentrasi. Hal ini dikarenakan pijatan yang baik dapat mengubah gelombang otak. Pengubahan ini terjadi dengan cara menurunkan gelombang alpha dan meningkatkan gelombang beta serta tetha yang dapat dibuktikan dengan penggunaan EEG (electro encephalogram).

Peningkatan lama tidur bayi yang merupakan salah satu indikator kualitas tidur bayi karena pemijatan disebabkan oleh adanya peningkatan kadar sekresi serotonin yang dihasilkan pada saat pemijatan. Serotonin merupakan zat transmitter utama yang menyertai pembentukan tidur dengan menekan aktivitas sistem pengaktivasi retikularis maupun aktivitas otak lainnya, serotonin yang disintesis dari asam aminb/alktiptidph mayighomg kdicdomatau tidak berkua menjadi 5-hidroksitriptophan (5HTP) kemudian menjadi $\mathrm{N}$-asetil serotonin yang pada akhirnya berubah menjadi melatonin. Pijat dapat mempengaruhi keluarnya hormon tidur (melatonin), dimana dengan hormon tersebut bayi dapat memiliki pola tidur yang teratur.

Melatonin adalah hormon utama yang dihasilkan oleh kelenjar pineal. Sekresinya distimulasi oleh gelap dan dihambat oleh cahaya, melatonin ini meningkat pada malam hari, produksi melatonin meningkat bila reseptor sel tubuh manusia menangkap pesan bahwa intensitas cahaya mulai berkurang. Manfaat lain melatonin adalah sebagai antioksidan yang larut dalam lemak dan air, meningkatkan imun tubuh, menimbulkan relaksasi otot dan menghilangkan ketegangan. Pemijatan yang diberikan akan terjadi dilatasi 
pembuluh darah, dimana sirkulasi darah akan meningkat. Sirkulasi darah yang lancar akan membutuhkan $\mathrm{O} 2$ yang lebih banyak dalam aliran darah, kebutuhan $\mathrm{O} 2$ yang meningkat akan dikirim ke seluruh tubuh, tidak terkecuali lebih banyak dikirim ke otak sehingga memacu sistem sirkulasi dan respirasi menjadi lebih baik. Proses ini akan meningkatkan jumlah tidur bayi yang merupakan salah satu indikator dari kualitas tidur bayi. Pemijatan bayi yang dilakukan sebelum waktu tidur membuat tubuh mendingin dan mempertahankan suatu keadaan kelelahan yang dapat meningkatkan relaksasi karena pemijatan dapat mempengaruhi keluarnya hormon tidur melatonin. Baby gym merupakan bentuk permainan gerakan yang bertujuan merangsang pertumbuhan dan perkembangan, serta kemampuan pergerakan bayi secara optimal. Dengan melakukan baby gym, yang dapat membuat aliran darah lancar, asam laktat didaur ulang, dan badan terasa segar, anak dapat mempergunakan waktunya untuk kegiatan sehingga jadwal tidurnya menjadi teratur. Karena tidur anak dapat tercukupi dan menjadi teratur. Tidur pun menjadi cukup sehingga dapat dikatakan bahwa baby gym dapat berkontribusi dalam peningkatan durasi tidur yang merupakan salah satu indikator kualitas tidur bayi (Tiffany, 2015).

Upaya yang sudah dilakukan oleh tenaga kesehatan adalah Pemberian pendidikan kesehatan tentang cara mengatasi gangguan tidur. Kebanyakan dari ibu-ibu di Desa Talang tidak mengerti bahwa pijat bayi membuat kualitas tidur bayi baik. Mereka hanya akan membawa bayinya ke dukun bayi untuk dipijat pada saat bayi sedang sakit. Tujuan penelitian ini adalah untuk menganalisa efektifitas baby massage dan baby gym terhadap kualitas tidur bayi usia $3-6$ bulan di Desa Talang Kabupaten Tegal.

\section{METODE}

Penelitian ini adalah quasi eksperiment dengan desain penelitian yaitu two grup pre and post test with control design. Sampel dalam penelitian ini sebanyak 34 bayi dibagi menjadi 2 kelompok masing -masing kelompok
17 responden. Kriteria inklusinya adalah bayi sehat usia $3-6$ bulan dan tidak panas, sedangkan kriteria ekslusinya adalah bayi yang mengalami kelainan fisik dan bayi lahir dengan berat badan lahir rendah. Pelaksanaan penelitian dilakukan dengan: baby massage 3 kali seminggu dalam waktu 15 menit dan diberikan selama 2 minggu pada kelompok baby massage dan baby gym 3 kali seminggu dalam waktu 5 menit selama 2 minggu pada kelompok baby gym. Menggunakan SOP baby massage dan SOP baby gym serta lembar observasi kualitas tidur yang meliputi : bayi tidur lebih dari 9 jam pada malam hari, bayi terbangun pada malam hari tidak lebih dari 3 kali, bayi bisa tidur lagi setelah terbangun pada malam hari tidak lebih dari 1 jam, bayi terbangun pagi harinya dalam kondisi ceria tidak rewel. Analisa data menggunakan Uji Wilcoxon dan Mann Whithney karena data berdistribusi tidak normal.

\section{HASIL}

Tabel 1. Kualitas tidur pada bayi usia 3-6 bulan sebelum dan sesudah baby massage

\begin{tabular}{llllllll}
\hline $\begin{array}{l}\text { Kualitas } \\
\text { Tidur }\end{array}$ & $n$ & Mean & Median & Min & Max & $\begin{array}{l}\text { P. } \\
\text { Value }\end{array}$ \\
\hline $\begin{array}{lllllll}\text { Sebelum } \\
\text { Sesudah }\end{array}$ & 17 & 2 & 2 & 0 & 4 & \\
\hline
\end{tabular}

Tabel 1. menunjukkan sebelum dilakukan baby massage nilai rata rata 2 dan sesudah 3,4. dengan p-value adalah 0,000 yang artinya ada pengaruh baby massage terhadap kualitas tidur bayi.

Tabel 2 Kualitas tidur pada bayi usia 3-6 bulan sebelum dan sesudah baby gym

\begin{tabular}{|c|c|c|c|c|c|c|}
\hline $\begin{array}{l}\text { Kualitas } \\
\text { Tidur }\end{array}$ & $n$ & Mean & Median & Min & Max & $\begin{array}{l}\text { P. } \\
\text { Value }\end{array}$ \\
\hline \multirow{2}{*}{$\begin{array}{l}\text { Sebelum } \\
\text { Sesudah }\end{array}$} & \multirow[b]{2}{*}{17} & 2,1 & 2 & 0 & 4 & \multirow[b]{2}{*}{0,001} \\
\hline & & 3,4 & 4 & 2 & 4 & \\
\hline
\end{tabular}


Tabel 2. menunjukkan data nilai rata rata 2,1 sebelum dilakukan baby gym dan nilai rata rata sesudah baby gym adalah 3,4 dengan p-value 0,001 sehingga ada pengaruh baby gym terhadap kualitas tidur bayi.

Tabel 3. Efektifitas kualitas tidur sesudah diberikan baby massage dan baby gym pada tidur bayi usia 3-6 bulan

\begin{tabular}{llll}
\hline Kualitas Tidur & $\mathrm{n}$ & Mean Rank & P. Value \\
\cline { 1 - 2 } Baby Massage & 17 & 18,62 & \\
\cline { 1 - 2 } & & 16,475 \\
\end{tabular}

Berdasarkan tabel 3. tersebut dapat diketahui bahwa $p$-value $=0,475$ yang artinya tidak ada perbedaan efektivitas antara baby massage dan baby gym terhadap kualitas tidur bayi usia 3-6 bulan di Desa Talang Kecamatan Talang Kabupaten Tegal, maka baby massage dan baby gym memberikan efek yang sama yaitu sama sama efektif terhadap kualitas tidur bayi usia 3-6 bulan di Desa Talang Kecamatan Talang Kabupaten Tegal.

\section{PEMBAHASAN}

Nilai setiap aspek kualitas tidur bayi sebelum dan sesudah perlakuan dapat dilihat dari empat aspek yaitu: lama tidur bayi, jumlah bayi terbangun, lama bayi terbangun, dan kondisi bayi. Aspek-aspek tersebut menggambarkan apakah bayi mengalami gangguan tidur ataukah tidak dari beberapa segi, bayi dikatakan mengalami gangguan tidur apabila tidur kurang dari 9 jam, terbangun lebih dari 3 kali, terbangun lebih dari 1 jam, dan kondisi bayi yang terlihat selalu rewel dan menangis

Hasil penelitian dapat diketahui bahwa sebelum dilakukan pijat bayi pada sebanyak 17 responden, jumlah total nilai 4 aspek kualitas tidur adalah 34, nilai mean 2, mediannya adalah 2 dengan nilai maksimum 4 dan nilai minium 0 . Sedangkan sesudah perlakuan pijat bayi pada sebanyak 17 responden, jumlah total nilai 4 aspek kualitas tidur adalah 58 , nilai mean 3.4 dan median 4 , nilai maksimum 4 dan nilai minimum 2. Jika dibandingkan sebelum dengan sesudah perlakuan pijat bayi maka terjadi kenaikan nilai kualitas tidur bayi usia 3-6 bulan yaitu naik dari nilai 34 menjadi 58 atau meningkat sebesar 24 sedangkan nilai mean naik dari 2 menjadi 3,4 dan mediannya juga naik dari 2 menjadi median 4.

Data penelitian nilai aspek kualitas tidur bayi dari sebelum dan sesudah dilakukan pijat bayi terjadi peningkatan. Lama tidur bayi sebelum dan sesudah perlakuan pijat bayi menunjukkan peningkatan nilai dari 8,00 menjadi 13,00 sehingga terjadi kenaikan nilai sebesar 4,00 poin.

Data berikutnya adalah nilai jumlah bayi terbangun, sebelum dan sesudah pijat bayi adalah 8,00 dan 16,00 , sehingga terjadi peningkatan sebesar 8,00 poin..

Data nilai lama bayi terbangun sebelum dan sesudah pijat bayi adalah sebesar 11,00 dan 15,00 , sehingga terjadi peningkatan nilai lama bayi terbangun sebanyak 4,00 poin.

Adapun data kondisi bayi juga terjadi peningkatan dari sebelum dan sesudah pijat bayi, nilai kondisi bayi sebelum pijat bayi adalah sebesar 7,00 dan sesudah pijat bayi sebesar 14,00 sehingga terjadi peningkatan sebesar 7,00 poin. Dari data tersebut di atas peningkatan yang paling banyak pada responden adalah pada kondisi bayi terlihat bugar setelah dipijat yaitu awalnya hanya 7 responden menjadi 14 responden setelah dipijat.

Hasil penelitian dapat diketahui bahwa sebelum dilakukan baby gym pada sebanyak 17 responden, jumlah total nilai 4 aspek pada kualitas tidur adalah 37, nilai mean 2.1 dan mediannya 2, nilai maksimum 4 dan nilai minium 0. Sedangkan sesudah perlakuan pijat bayi pada sebanyak 17 responden, jumlah total nilai 4 aspek kualitas tidur adalah 58 , nilai mean 3.4 dan mediannya adalah 4 , nilai maksimum 4 dan nilai minimum 2 . Jika dibandingkan sebelum dengan sesudah perlakuan pijat bayi maka terjadi kenaikan nilai kualitas tidur bayi usia 3-6 bulan yaitu jumlah total nila 4 aspek kulaitas tidur 37 menjadi 58 atau naik sebesar 21.

Data penelitian nilai aspek kualitas tidur bayi dari sebelum dan sesudah dilakukan baby gym terjadi peningkatan. Lama tidur bayi sebelum dan sesudah perlakuan baby gym 
menunjukkan peningkatan nilai dari 6,00 menjadi 15,00 sehingga terjadi kenaikan nilai sebesar 9,00 poin.

Data berikutnya adalah nilai jumlah bayi terbangun, sebelum dan sesudah baby gym adalah 14,00 dan 16,00, sehingga terjadi peningkatan sebesar 2,00 point. Data nilai lama bayi terbangun sebelum dan sesudah baby gym adalah sebesar 9,00 dan 14,00, sehingga terjadi peningkatan nilai lama bayi terbangun sebanyak 5,00 poin. Data kondisi bayi juga terjadi peningkatan dari sebelum dan sesudah baby gym, nilai kondisi bayi sebelum baby gym adalah sebesar 8,00 dan sesudah pijat bayi sebesar 13,00 sehingga terjadi peningkatan sebesar 4,00 poin.

Dari data tersebut di atas peningkatan yang paling banyak pada responden adalah pada kondisi bayi terlihat bugar setelah dipijat yaitu awalnya hanya 8 responden menjadi 13 responden setelah dipijat.

Hasil perhitungan Uji Wilcoxon menunjukkan hasil bahwa nilai $p$-value adalah $0,000 \leq 0,05$, sehingga dapat disimpulkan bahwa Ha diterima dan Ho ditolak, atau dapat dikatakan bahwa terdapat pengaruh yang signifikan perlakuan pijat bayi terhadap kualitas tidur bayi usia 3-6 bulan di Desa Talang Kecamatan Talang Kabupaten Tegal. Hasil perhitungan Uji Wilcoxon menunjukkan hasil bahwa nilai $p$-value adalah $0,001 \leq 0,05$, maka terdapat pengaruh yang signifikan perlakuan baby gym terhadap kualitas tidur bayi usia 3-6 bulan di Desa Talang Kecamatan Talang Kabupaten Tegal.

Berdasarkan hasil perhitungan Uji Mann Withney dapat diketahui bahwa $\mathrm{p}$-value = 0,475 , dimana $0,475>0,05$ sehingga hipotesis bahwa ada perbedaan efektivitas pijat bayi dan baby gym terhadap kualitas tidur bayi ditolak. Kesimpulan yang dapat ditarik dari ditolaknya hipotesis ini adalah bahwa tidak ada perbedaan antara pijat bayi dan baby gym terhadap kualitas tidur bayi di Desa Talang Kecamatan Talang Kabupaten Tegal.

Tidak adanya perbedaan antara pijat bayi dan baby gym terhadap kualitas tidur bayi kemungkinan disebabkan oleh kedua perlakuan tersebut oleh pemijat, sama-sama merupakan terapi sentuh dengan memberikan sentuhan yang cukup intens pada bayi sehingga bayi merasa rileks yang menyebabkan bayi lebih mudah tertidur. Mengingat akan pentingnya waktu tidur bagi perkembangan bayi, maka kebutuhan tidurnya harus benar-benar terpenuhi agar tidak berpengaruh buruk terhadap perkembangannya.

Salah satu cara yang dapat digunakan untuk memenuhi kebutuhan tersebut adalah dengan pijat bayi. Bayi yang dipijat akan dapat tidur dengan lelap, sedangkan pada waktu bangun, daya konsentrasinya akan lebih penuh. Salah satu terapi non farmakologis untuk mengatasi masalah tidur bayi adalah baby massage.

Baby Massage merupakan salah satu jenis stimulasi yang akan merangsang perkembangan struktur maupun fungsi dari kerja sel-sel dalam otak.Pijatan lembut akan membantu mengendurkan otot-ototnya sehingga bayi menjadi tenang dan tidurnya nyenyak. Sentuhan lembut pada bayi merupakan sarana ikatan yang indah antara bayi dan orang tuanya. Bayi yang dipijat selama kurang lebih 15 menit akan merasa lebih rileks, tidur lebih lelap, perkembangan dan pertumbuhannya juga semakin baik. Saat bayi dipijat akan muncul hormon endorphin yang akan meningkatkan pertumbuhan dan perkembangan bayi serta Hormon Serotonin yang akan membuat bayi lebih nyaman dan tumbuh lebih baik.

Hasil penelitian ini memiliki kesejajaran hasil dengan penelitian AlHazmi berjudul Perbedaan Pengaruh Senam Bayi Dengan Pijat Bayi Dalam Meningkatkan Motorik Kasar Pada Anak Usia 3-12 Bulan Di Posyandu Modinan Yogyakarta yang memberikan kesimpulan bahwa tidak ada perbedaan pengaruh pijat bayi dan senam bayi (baby gym) dalam meningkatkan motorik kasar pada anak usia 3-12 bulan. Pijat bayi dan baby gym merupakan pengungkapan kasih sayang antara orang tua dengan anak lewat sentuhan kasih. 
Sentuhan dan pelukan merupakan kebutuhan dasar bayi. Selain melakukan pijatan pada bayi, bayi juga dapat dituntun untuk dapat melakukan gerakan-gerakan senam sebagai bagian dari stimulus atau rangsangan-rangsangan untuk pertumbuhan motorik bayi. Pada dasarnya pijat bayi dan baby gym (senam bayi) dapat diberikan sedini mungkin. Apalagi besarnya manfaat yang dapat diperoleh antara lain: kedekatan orang tua dengan bayi, bayi merasa terlindungi dan dicintai, memperkuat ikatan batin orang tua dengan bayi, mendidik bayi untuk tenang dalam menghadapi stres dan optimalisasi tumbuh kembang bayi.

Menurut peneliti pijat bayi dan baby gym dapat dilakukan secara rutin agar perkembangan motorik bayi lebih optimal. Semua itu memiliki dampak yang luar biasa bagi perkembangan bayi termasuk dalam kualitas tidur bayi (Hazmi, 2017).

Baby gym (senam bayi) yang dikenal dengan beberapa istilah seperti baby gym, senam bayi, olahraga bayi, atau yoga bayi pada dasarnya merupakan olah tubuh yang banyak melibatkan anggota badan. Itu sebabnya banyak organ tubuh yang turut memetik manfaat, di antaranya adalah merilekskan tubuh bayi sehingga bayi lebih mudah tidur dan tidak rewel.

Kualitas tidur bayi dipengaruhi oleh beberapa faktor. Kualitas tersebut dapat menunjukkan adanya kemampuan individu untuk tidur dan memperoleh jumlah istirahat sesuai dengan kebutuhannya. Hubungan tersebut, yaitu adanya pengaruh pijat bayi terhadap kualitas tidur bayi usia 3-6 bulan, didukung oleh teori yang dikemukakan oleh Nazwa yang menyatakan bahwa pijat pada anak sangat baik bagi kesehatannya.

Pemijatan membuat anak lebih santai dan tenang sehingga bisa meningkatkan efektivitas tidurnya, mengurangi stress dan tekanan, pijatan menenangkan dan menurunkan produksi hormone adrenalin yang selanjutnya akan meningkatkan daya tahan tubuh bayi. Pijatan yang lembut membantu tubuh melepaskan oksitosin dan endorphin, kedua hormon itu dapat membantu mengatasi ketidaknyamanan yang dirasakan bayi.
Meningkatkan konsentrasi bayi, umumnya bayi yang dipijat akan tertidur lebih lelap sehingga pada waktu bangun konsentrasinya akan lebih penuh (Nazwa, 2015).

Hasil penelitian ini sesuai dengan penelitian Fauziyah Rohmawati yang meneliti tentang pengaruh baby message (pijat bayi) terhadap kualitas tidur bayi yang menyimpulkan bahwa terdapat pengaruh baby massage terhadap kualitas tidur bayi. Demikian pula hasil penelitian Bintang Aji Pamungkas yang melakukan penelitian dengan judul Pengaruh pijat bayi terhadap kualitas tidur bayi umur 0-6 bulan di Puskesmas Kartasura memberikan hasil yang sejalan dengan penelitian ini bahwa terdapat pengaruh pijat bayi terhadap kualitas tidur bayi umur 0-6 bulan (Rohmawati, 2019).

Nurella Handayani yang meneliti tentang pengaruh pijat bayi terhadap kualitas tidur bayi usia 3-5 bulan di Desa Plalangan dan Desa Ajung Kecamatan Kalisat Kabupaten Jember tahun 2015 juga mendukung hasil penelitian ini. Penelitian ini menggunakan Quasy-Experiment dengan rancangan posttest only control group design dengan hasil penelitian dari 30 sampel rata-rata nilai tertinggi didapat olek kelompok perlakuan dengan kategori baik sebanyak 86,7\% sedangkan pada kelompok kontrol jumlah terbanyak adalah responden dengan kualitas tidur cukup 66.7\%. Hasil analisis uji Mann Whitney diperoleh nilai p-value yaitu $0,003 \leq \alpha \quad 0,05$ maka dapat disimpulkan $\mathrm{H} 1$ diterima yang berarti terdapat pengaruh yang signifikan antara pijat bayi terhadap kualitas tidur bayi usia 3-5 bulan (Handayani, 2015).

Mengingat akan pentingnya waktu tidur bagi perkembangan bayi, maka kebutuhan tidurnya harus benar-benar terpenuhi agar tidak berpengaruh buruk terhadap perkembangannya. Salah satu cara yang dapat digunakan untuk memenuhi kebutuhan tersebut adalah dengan pijat bayi. Bayi yang dipijat akan dapat tidur dengan lelap, sedangkan pada waktu bangun, daya konsentrasinya akan lebih penuh.

Salah satu terapi non farmakologis untuk mengatasi masalah tidur bayi adalah baby massage. Baby Massage merupakan salah satu jenis stimulasi yang akan 
merangsang perkembangan struktur maupun fungsi dari kerja sel-sel dalam otak (Aji, 2016).

\section{KESIMPULAN DAN SARAN}

Terdapat pengaruh pijat bayi terhadap kualitas tidur bayi usia 3-6 bulan di Desa Talang Kecamatan Talang Kabupaten Tegal; Terdapat pengaruh baby gym terhadap kualitas tidur bayi usia 3-6 bulan di Desa Talang Kecamatan Talang Kabupaten Tegal dan Tidak terdapat perbedaan efektivitas pijat bayi dan baby gym terhadap kualitas tidur bayi usia 3-6 bulan di Desa Talang Kecamatan Talang Kabupaten Tegal.

Orang tua bayi disarankan untuk memberikan pijat bayi selama 15 menit atau baby gym selama 5 menit tiga kali dalam seminggu minggu baik dilakukan sendiri maupun dibawa ke tempat pijat bayi dan baby gym untuk peningkatan kualitas tidur bayinya.

Bagi Bidan Desa diharapkan ada layanan untuk pijat bayi dan baby gym untuk meningkatkan pelayanan pada masyarakat terutama dalam hal kualitas tidur bayi usia 3-6 bulan.

\section{REFERENSI}

Aji, P.B., (2016). "Pengaruh Pijat Bayi Terhadap Kualitas Bayi Umur 0-6 Bulan Di Puskesmas Kartasura," Univ. Muhammadiyah, p. 2.

Handayani, N., (2015) "Pengaruh Pijat Bayi Terhadap Kualitas Tidur Bayi Usia 3-5 Bulan di Desa Plalangan dan Desa Ajung Keacamatan Kalisat Kabupaten Jember,"

Hazmi, F., (2017). "Perbedaan pengaruh senam bayi dengan pijat bayi dalam meningkatkan motorik kasar pada anak usia 3-12 bulan di posyandu modinan yogyakarta," Univ. Aisyiyah Yogyakarta. [Online]. Available: http://digilib2.unisayogya.ac.id/xmlui/handle/123 456789/1730.

Griya Sehat Indonesia, (2015)., Baby Spa Training (Baby Massage, Baby Swim and Baby gym). Malang: Griya Sehat Indonesia.

Nazwa.N.U., (2015). Rahasia lbu Pintar, Panduan Merawat Bayi Pasca Persalinan Sampai 12 Bulan. Yogyakarta: Katahati Notoatmodjo..

Rohmawati, F., (2019) "Pengaruh Baby Massage Terhadap Kualitas Tidur Bayi Usia 3-12 Bulan (Di Ponkesdes Desa Grogol, Kecamatan Diwek, Kabupaten Jombang)," J. Kebidanan, vol. 9, no. 2, pp. 108-113.

Satte, S., (2017). "Predictors of Sleep Disturbancesin the First Year of Life : a Longitudinal Study,"

Simanungkalit. H.M,, (2019) "Pengaruh Pijat Bayi Terhadap Pola Tidur Bayi Usia 0-6 Bulan," Mahakam Midwifery J., vol. 4, no. 2, p. 18, doi: 10.35963/midwifery.v4i2.128 .

Tiffany.F,. (2015). "Newborn Massage Therapy.," Int. J. Pediatr. Neonatal Heal., 